\title{
Enzyme-Linked Lectin Assay
}

National Cancer Institute

\section{Source}

National Cancer Institute. Enzyme-Linked Lectin Assay. NCI Thesaurus. Code C147466.

An enzyme immunoassay that utilizes enzyme-lectin conjug ates to detect specific carbohydrate end groups on immobilized glycoproteins on microtiter plates. 